\title{
Nanotechnology-based drug delivery systems and herbal medicines: a review
}

\author{
This article was published in the following Dove Press journal: \\ International Journal of Nanomedicine \\ 6 December 2013 \\ Number of times this article has been viewed
}

\section{Bruna Vidal Bonifácio \\ Patricia Bento da Silva \\ Matheus Aparecido dos \\ Santos Ramos \\ Kamila Maria Silveira Negri \\ Taís Maria Bauab \\ Marlus Chorilli \\ School of Pharmaceutical \\ Sciences, Postgraduate Program in \\ Pharmaceutical Sciences, São Paulo \\ State University, Araraquara, Brazil}

Correspondence: Marlus Chorilli School of Pharmaceutical Sciences, Postgraduate Program in Pharmaceutical Sciences, São Paulo State University, Rodovia Araraquara-Jaú, km 0I, Araraquara, SP, CEP |480 |-902, Brazil $\mathrm{Tel}+55 \mathrm{I} 6330 \mathrm{I} 6998$

Fax +55 I6 330I 6760

Email chorilli@fcfar.unesp.br

\begin{abstract}
Herbal medicines have been widely used around the world since ancient times. The advancement of phytochemical and phytopharmacological sciences has enabled elucidation of the composition and biological activities of several medicinal plant products. The effectiveness of many species of medicinal plants depends on the supply of active compounds. Most of the biologically active constituents of extracts, such as flavonoids, tannins, and terpenoids, are highly soluble in water, but have low absorption, because they are unable to cross the lipid membranes of the cells, have excessively high molecular size, or are poorly absorbed, resulting in loss of bioavailability and efficacy. Some extracts are not used clinically because of these obstacles. It has been widely proposed to combine herbal medicine with nanotechnology, because nanostructured systems might be able to potentiate the action of plant extracts, reducing the required dose and side effects, and improving activity. Nanosystems can deliver the active constituent at a sufficient concentration during the entire treatment period, directing it to the desired site of action. Conventional treatments do not meet these requirements. The purpose of this study is to review nanotechnology-based drug delivery systems and herbal medicines.
\end{abstract}

Keywords: natural products, herbal medicines, nanotechnology, drug delivery systems, biological activity

\section{Introduction}

Knowledge and use of plants as herbal medicines has occurred in various populations throughout human evolution, beginning when man was learning to select plants for food, and to relieve ailments and diseases. ${ }^{1}$ However, during the second half of the twentieth century, especially in the Western world, herbal medicines were gradually replaced by allopathic medicines. Allopathic treatments are currently more widely used than traditional medicines, especially in developed countries. However, most developing countries continue to use these natural medicines, most likely because obtaining a synthetic drug is expensive. ${ }^{2}$ According to the World Health Organization, $80 \%$ of people in developing countries depend on traditional medicinal practices to meet and/or supplement their basic health needs. ${ }^{3}$

Currently, despite marketing and encouragement from the pharmaceutical industry during the development of allopathic medicines, a large segment of the population in many countries continues to utilize complementary practices for their health care. Many of these practices are derived from medicinal plants. However, due to economic, political, and social changes that have occurred worldwide, the therapeutic use of these natural resources, which are mainly used by people who cannot afford different treatments, has greatly diminished. ${ }^{1,4}$ 
Elucidating the chemical composition of medicinal plants and their popular uses has become a research focus for all scientific communities. This research may lead to increasingly innovative products, with fewer side effects than existing drugs. ${ }^{5}$ Furthermore, the enormous diversity of structures of natural products, as well as their physicochemical and biological properties, has impressed researchers. However, except when they are used for local health care needs, a low percentage of plants have been tested for their medicinal potential. Therefore, there is a lack of information to describe any true potential. ${ }^{6-8}$

The biological activity of medicinal plants from all over the world has been studied by several groups of researchers. These studies are based on the popular uses of different species, ${ }^{9}$ as well as on popular knowledge and scientific studies describing medical plant use, with a focus on how these plants could benefit the pharmaceutical industry. Approximately 50\% of the drugs approved during 1981-2006 were directly or indirectly derived from natural products. ${ }^{1}$

The chemical complexity of extracts is an extremely important consideration for the success of a formulation, because the formulation must also release the active ingredient. Consequently, vehicles must concurrently improve the solubility of the drug, minimize the degradation process, reduce any toxicity, and mask any bad taste, while controlling the active absorption and biological response..$^{10,11}$

Phytochemical and phytopharmacological sciences have already established the composition and biological activities of several medicinal plant products. Most of the biologically active constituents of extracts, such as flavonoids, tannins, and terpenoids, are highly water-soluble, but demonstrate a low absorption, because they are unable to cross lipid membranes, have high molecular sizes, and demonstrate poor absorption, resulting in loss of bioavailability and efficacy. Some studies have shown that herbal medicines have good activity in assays in vitro, which are not reproducible in experiments in vivo. Furthermore, some essential substances are rarely used, because they are incompatible with other components in the formulation, or have undesirable properties. ${ }^{12,13}$

Several nanotechnological strategies, such as polymeric nanoparticles, solid lipid nanoparticles (SLNs), liquid crystal (LC) systems, precursors systems for liquid crystals (PSLCs), liposomes, and microemulsions, have attempted to break this barrier; they allow substances with different properties to be used in the same formulation, and may even change a substance's properties and behavior in a biological environment. These technological discoveries have revolutionized drug delivery. The new drug delivery systems have the ability not only to increase the effectiveness of active components, but also to reintroduce other components that were discarded because they were not useful in formulation. Moreover, the ability to improve new substances, such as by increasing selectivity and efficacy, protecting against thermal- or photo-degradation, reducing side effects, and controlling the release of active constituents, before they are introduced to the market or used therapeutically, makes this approach even more attractive. ${ }^{13-16}$

Along with advances in recent decades related to drug development, there is an urgent need for developments in nanoscience and nanotechnology that relate to the use of nanoscale materials, which, to date, have only been a focus of the cosmetics industry. Scientific advances can revolutionize, and enhance, solutions to problematic aspects of formulation preparation. ${ }^{17}$ In addition to improving the solubility and stability of active constituents, nanostructures may extend a formulation's action, and successfully combine active substances with different degrees of hydrophilicity/lipophilicity. This technology can also be used to target the distribution of a substance toward specific tissues or organs. ${ }^{18-21}$

Pharmaceutical industries have become increasingly interested in nanotechnological advances because these developments provide advantages, such as modified release systems, and the potential to develop new formulations that were previously not possible (due to several aspects related to the active constituents)..$^{22}$

Although nanotechnology contributions are advantageous for several medicinal areas, it is essential to highlight some of the disadvantages. Clinical researchers have mentioned some negative factors, such as high cost, difficulty of scaling up processes, and the easy inhalability of nanoparticles, which can result in dangerous lung diseases, and often lead to other diseases that can lead to changes in homeostasis, or even death. ${ }^{23,24}$

The strategy of applying nanotechnology to plant extracts has been widely cited in the literature, because nanostructured systems could potentiate action of plant extracts, promote sustained release of active constituents, reduce the required dose, decrease side effects, and improve activity. ${ }^{25,26}$

Kesarwani and Gupta published a review that mentioned several studies which employed nanostructured systems to optimize the properties of plant extracts. ${ }^{10}$ Bhattacharya and Ghosh used lipid-based systems incorporated green tea and ginseng (Panax ginseng CA Meyer) (Araliaceae) extracts, in various formulations, to increase the absorption of the active components. ${ }^{27} \mathrm{Su}$ et al developed nanoparticles 
using Radix salvia miltiorrhiza Bunge (Lamiaceae), and noticed a significant improvement in bioavailability of the extract. ${ }^{28}$ Sinico et al developed liposomes with Artemisia arborescens L. (Asteraceae) and noted that these systems helped the active components from this plant penetrate the cytoplasmic viral barrier. ${ }^{29}$ Rajendran et al obtained nanoparticles using a methanolic extract of Ocimum sanctum L. (Lamiaceae) and reported that the encapsulated extract demonstrated better antimicrobial activity than in free-form preparation, when tested against Escherichia coli, Bacillus subtilis, Pseudomonas aeruginosa, and Staphylococcus aureus. ${ }^{26}$

The effectiveness of medicinal plant species, or herbal medicine, depends on the supply of active compounds. Therefore, new carriers should deliver the active constituent at a sufficient concentration during the entire treatment period, and direct it toward the desired target, because these requirements are not completely obtained by conventional treatments. Partial or total loss of a specific activity can be observed when constituents of an extract are isolated or purified. Moreover, some components are highly sensitive to the acidic $\mathrm{pH}$ of the stomach, which promotes their destruction, and loss of the desired effect, after ingestion. Some extracts are not used clinically because of these obstacles. ${ }^{12}$

Using different drug delivery systems based on nanotechnology, such as polymeric nanoparticles, solid lipid nanoparticles (SLNs), liquid crystal (LC) systems, precursor systems for liquid crystals (PSLCs), liposomes, and microemulsions, is an interesting approach to improve a formulation's most desirable properties. ${ }^{10,30}$ Furthermore, nanoscale particles may represent a future where activity is ensured, and the problems associated with using medicinal plants are overcome. ${ }^{12}$

\section{Polymeric nanoparticles}

Currently, nanotechnological processes involving medicinal plants have gained the focus of researchers, who have developed several innovative delivery systems, including polymeric nanoparticles. These materials, made from biodegradable and biocompatible polymers, represent an option for controlled drug delivery. Polymeric nanoparticles are a promising formulation used for drug delivery systems, because they can be targeted. . $^{31,32}$

Polymeric nanoparticles are colloidal systems that work as vectors to control drug release, targeting it toward specific locations. Compared against conventional formulations, polymeric nanoparticles can increase the solubility of constituents, reduce the therapeutic dose, and improve absorption of the active components. Furthermore, nanoparticles are advantageous when used in blood, because they are stable, non-toxic, nonthrombogenic, nonimmunogenic, noninflammatory, do not activate neutrophils, and avoid the reticuloendothelial system. Sometimes, polymeric nanoparticles are used to reach specific tissues, or work as a cell surface. ${ }^{12,33-35}$ Polymeric nanoparticles can be synthesized using various methods, according to their intended application and payload. These particles are made from natural, or artificial, biodegradable polymers. Natural materials are preferred, because they generally have more advantages, such as the ability to deliver more than one active constituent using the same carrier, increase residence time in the body, provide a sustained release system, and reduce side effects. ${ }^{35}$

Nanoscale systems are also known as submicrometer, because particle diameters are $<1 \mu \mathrm{m}$. They provide various therapeutic advantages in several areas, including routes of administration, site specificity, and increased therapeutic effect, which makes them desirable to researchers. Oral administration of certain conventional formulations may lead to side effects, and the degradation of active constituents is promoted by the acidic $\mathrm{pH}$ of the stomach. These problems might be reduced by polymeric nanoparticles. In ophthalmic administration, nanoparticles control the release of active constituents, increasing ocular bioavailability, and reducing side effects. ${ }^{34}$

Polymeric nanoparticles can range from 10-1,000 nm in diameter, while still protecting drugs efficiently. They can appear as nanocapsules (NCs) and nanospheres (NSs); these structures differ in their composition and structural organization. Nanocapsules contain an oily core surrounded by a polymeric membrane; the active constituent can be adsorbed to the polymeric membrane and/or dissolved in the oily core. Nanospheres are made only from a polymeric structure, where the active constituent is retained or adsorbed. Although there is increasing search for new types of polymers, some of them have already been used extensively for polymeric nanoparticles, including poly-L-lactic acid (PLA) and copolymers with glycolic acid (PLGA). ${ }^{12,33,34}$

The most important methods used to produce polymeric nanoparticles are broadly classified as follows: the in situ polymerization method, with dispersed monomers (alkyl cyanoacrylate), or a method of precipitation of preformed polymers, such as poly(lactic acid) (PLA), poly(lactic-coglycolic acid) (PLGA), poly( $\varepsilon$-caprolactone) (PCL), methacrylic acid copolymers, and acrylic or methacrylic esters. Regardless of the chosen method, the products are obtained as aqueous colloidal suspensions. However, some problems can obstruct industrial applicability, for example: nanoparticle 
precipitation and physicochemical stability problems can be reduced through drying processes, such as sublimation (freeze drying), that allow dehydration, while preventing particle aggregation. ${ }^{34}$

Some characteristics of colloidal nanoparticles cause technical difficulties during physicochemical characterization; this includes morphological evaluation, particle size, molecular weight distribution, zeta potential, $\mathrm{pH}$ determination, drug concentration inside the nanostructures, drug release kinetics, and stability over an extended period of time. ${ }^{34}$

Das et al tested the root extract of Phytolacca decandra (Phytolaccaceae) in free form (PD) and PLGA-encapsulated forms (NPD) in mice dosed with benzo[a]pyrene (BaP) $(25 \mathrm{mg} / \mathrm{kg})$ and sodium arsenite (SA) $(10 \mathrm{mg} / \mathrm{kg})$ in vivo, as well as on A549 lung cancer cells in vitro. The nanoencapsulation of PD increased the drug's bioavailability, and generated better chemopreventive action against lung cancer in vivo, and on A549 cells in vitro, than free form PD. ${ }^{36}$

Rajendran et al evaluated the antimicrobial activity of ethanolic, methanolic, petroleum ether, and aqueous extracts of leaves of Ocimum sanctum (Lamiaceae) (OS). They used an agar diffusion and microdilution technique to determine the minimum inhibitory concentration (MIC) against $B$. subtilis, $S$. aureus, E. coli, P. aeruginosa, Aspergillus niger, and Penicillium spp.; the best result was present to the methanolic extract, following by ethanol, petroleum ether and aqueous extracts.

After this screening, methanolic extracts demonstrated the best antimicrobial activity, and were loaded into sodium alginate chitosan nanoparticles (OSN), through a cationinduced, controlled gelation method. The particles were deposited on cotton fabric, using a pad dry cure method. ${ }^{26}$ Compared to OS and nanoparticles only, OSN demonstrated better and longer lasting antimicrobial activity than the unloaded formulation, producing cotton fabrics with excellent antimicrobial activity. ${ }^{26}$

One of most significant difficulties in chemotherapy is the inability to deliver the active constituent, in appropriate doses, to specific sites affected by the disorder. Currently, several of the antitumor therapeutics to be found in polymeric nanoparticle formulations have been evaluated in preclinical and clinical studies. Polymeric nanoparticles address problems found in chemotherapy by reducing toxicity, due to the protective barrier that prevents interaction between the active constituents and healthy cells. ${ }^{37}$

Curcumin is a yellow polyphenol, extracted from rhizomes of Curcuma longa (Zingiberaceae); it has demonstrated potent antitumor properties, in several studies involving human tumor cells, and animal models of carcinogenesis. This active constituent is highly potent, and nontoxic. The bioactive agent, found in turmeric, is used as an alternative drug for treating several disorders. However, its clinical applications are limited, because it has low aqueous solubility and bioavailability.

Various studies of polymeric nanoparticles have solved some formulation problems, such as the hydrophobic properties of some constituents, such as curcumin. Bisht et al synthesized a mixture containing curcumin-loaded polymeric nanoparticles, using aggregated structures containing randomly crosslinked copolymers of $\mathrm{N}$-isopropylacrylamide, N-vinyl-2-pyrrolidone, and poly(ethylene glycol) monoacrylate. Physicochemical characterization, via dynamic light scattering and transmission electron microscopy (TEM) measurements, confirmed that these polymeric nanoparticles had a favorable size distribution of $50 \mathrm{~nm}$. The curcuminloaded polymeric nanoparticles were called "nanocurcumin" (as opposed to "free curcumin"), and were easily dispersed in aqueous media. Nanocurcumin revealed therapeutic efficacy in vitro against various human pancreatic tumor cells, confirmed by cell viability and clonogenic assays. Nanocurcumin's mechanism of action against pancreatic cancer cells was as follows: free curcumin was released, inducing apoptosis, blocking the activation of nuclear factor kappa B (NFkB) and regulating levels of proinflammatory cytokines, such as interleukin 6 , interleukin 8 , and the tumor necrosis factor. Nanocurcumin provided an opportunity to extend the clinical use of curcumin via aqueous dispersion. ${ }^{38}$

In studies by Mukerjee and Vishwanatha, curcumin was encapsulated in PLGA nanospheres, using a solid/oil/water emulsion solvent evaporation method, and was evaluated for activity against prostate cancer. The encapsulation efficiency was $90.88 \% \pm 0.14 \%$, and the average particle size was $45 \mathrm{~nm}$. The results of the MTT cell viability assay for the curcuminloaded PLGA nanoparticles on prostate cancer cell lines, LNCaP, PC3, and DU145, and a nontumorigenic cell line, (PWR1E) showed $\mathrm{IC}_{50}$ reduced to $20-22.5 \mu \mathrm{M}$, while the range for free curcumin was $32-34 \mu \mathrm{M}$ - a $35 \%$ reduction was observed when curcumin was encapsulated. ${ }^{39}$

Bhawana Basniwal et al developed a new method to prepare curcumin-loaded polymeric nanoparticles, which improved curcumin's water solubility. ${ }^{40}$ The study also assessed whether this formulation would enhance curcumin's antimicrobial activity. Curcumin-loaded polymeric nanoparticles (nanocurcumin) were prepared using a process based on the wet-milling technique; nanoparticles were obtained with a narrow size 
distribution of 2-40 nm. Nanocurcumin's chemical structure was identical to the original molecule (curcumin), proving that no chemical change had occurred during encapsulation, and showing that the formulation could be easily dispersed in water without surfactant. Antimicrobial activity was evaluated using a microplate dilution technique against $S$. aureus, B. subtilis, E. coli, P. aeruginosa, Penicillium notatum, and A. niger. The water solubility and small size of nanocurcumin nanoparticles enhanced antimicrobial activity, relative to free curcumin. The antibacterial activity of nanocurcumin was more pronounced than its antifungal activity. Among bacteria, gram-positive strains were more sensitive. TEM analysis revealed that when the nanoparticles were introduced into a bacterium, they completely destroyed the cell wall, resulting in bacterial cell death. ${ }^{40}$

Honokiol (HN) is a constituent of the Chinese medicinal plant Magnolia officinalis (Magnoliaceae): 3',5-di(2-propenyl)-1,1'-biphenyl-2,4'-diol. It has several pharmacological effects, including anti-inflammatory, antithrombotic, antirheumatic, antioxidant, with anxiolytic, central nervous system depressant, and muscle relaxant activities. In addition, it has potent antitumor activity. Again, this compound's hydrophobic properties represent an obstacle, because high hydrophobicity prevents vascular administration. However, when this active constituent was loaded in polymeric nanoparticles, vascular administration was possible, as shown by Zheng et al. They developed a new formulation containing $\mathrm{HN}$-loaded polymeric nanoparticles for vascular administration, obtaining better results, relative to free HN. ${ }^{41}$

Khuda-Bukhsh et al formulated polymeric nanocapsules containing coumarin (7-hydroxy-6-methoxy) (HMC), which was isolated from an ethanolic extract of Gelsemium sempervirens J. St.-Hil (Gelsemiaceae). According to the in vitro evaluations, HMC has a pronounced anti-tumoral activity, but further studies were discontinued because of its hydrophobicity. A new formulation containing HMC-loaded polymeric nanoparticles demonstrated much better bioavailability than the free active constituent. ${ }^{31}$

Harungana madagascariensis Lam. Ex Poir (Hypericaceae) is widely known for its antibacterial, antifungal, and antiviral properties. Moulari et al evaluated and compared the in vitro and ex vivo antibacterial activity of ethanolic extract of $H$. madagascariensis leaf (HLE), incorporated into poly(D,L-lactide-co-glycolide) (PLG) nanoparticles (PLG-NPs) (HLE-PLG-NP). Two concentrations of HLE $(500 \mu \mathrm{g} / \mathrm{mL}$ and $1,000 \mu \mathrm{g} / \mathrm{mL})$ were evaluated for the in vivo assay; one concentration $(500 \mu \mathrm{g} / \mathrm{mL})$ was tested ex vivo, against two gram-positive bacteria ( $S$. epidermidis and Micrococcus luteus) and one gram-negative bacterial strain strain (Moraxella $s p$.). Ex vivo antibacterial activity was evaluated for $S$. epidermidis CIP 55109 using an artificial contamination method. The microorganism was inoculated for 12 hours on human skin fragment surfaces treated with HLE-PLG-NP, empty PLG-NPs, or HLE solution. In vitro studies revealed that both formulations completely reduced the bacterial growth of all strains tested, at $1,000 \mu \mathrm{g} / \mathrm{mL}$ concentrations. However, the $500 \mu \mathrm{g} / \mathrm{mL}$ HLE solution did not have a significant antibacterial activity against $S$. epidermidis, $M$. luteus, or Moraxella sp., relative to HLE- PLG-NP. During ex vivo evaluation, 4 hours after artificial contamination, HLE-PLG-NP $(500 \mu \mathrm{g} / \mathrm{mL})$ showed better antibacterial activity than HLE solution. A thin-layer chromatographic analysis revealed that, of the seven components found in the chromatogram of the HLE solution, only two were found in the HLE-loaded nanoparticles, including the flavonoid fraction, which is responsible for the antibacterial properties. Once again, results improved when extracts were loaded into polymeric nanoparticles. ${ }^{42}$

In 2006, Moulari et al investigated the in vitro antibacterial activity of the ethyl acetate extract from $H$. madagascariensis leaves against the major oral bacterial strains responsible for dental caries and gingivitis. To enhance antibacterial activity, HLE was loaded within PLG-NPs. Antibacterial activity was assessed via a dilution technique, using microplates, and polymeric nanoparticles were formulated using an interfacial polymer deposition solvent diffusion method. Free HLE displayed good results against most of the bacterial strains tested, with a $500 \mu \mathrm{g} / \mathrm{mL}$ MIC. The exception was Lactobacillus casei. However, HLE-PLG-NP was more effective (MIC: $187.5 \mu \mathrm{g} / \mathrm{mL}){ }^{43}$

Yen et al used a nanosuspension method to prepare Cuscuta chinensis Lam. (Convolvulaceae) nanoparticles (CN-CE), and compared the hepatoprotective and antioxidant effects of ethanolic extract from seeds of Cuscuta Chinensis (CE) and $\mathrm{CN}-\mathrm{CE}$ on acute liver injury in rats, induced by acetaminophen and oxidative stress. The levels of aspartate aminotransferase (AST), alanine aminotransferase (ALT), and alkaline phosphatase (ALP) were determined, to evaluate hepatoprotective effects, and examine histopathological sections of the liver, all of which are associated with hepatic integrity. The effects of the substances on the antioxidant enzymes and lipid peroxidation of the liver were also studied by assessing changes in superoxide dismutase (SOD), catalase (CAT), glutathione peroxidase (GPx) and malondialdehyde (MDA) levels. The levels of AST, ALT, and ALP were reduced by 
similar amounts, with oral doses of $\mathrm{CE}$ at $125 \mathrm{mg} / \mathrm{kg}$ and $250 \mathrm{mg} / \mathrm{kg}$, and of CN-CE at $25 \mathrm{mg} / \mathrm{kg} 50 \mathrm{mg} / \mathrm{kg}$, because this reduction is caused by the hepatoprotective effect. The antioxidant activity of SOD, CAT, and GPx was increased with free $\mathrm{CE}$ and $\mathrm{CN}-\mathrm{CE}$, while that of MDA was reduced. The effects of $50 \mathrm{mg} / \mathrm{kg} \mathrm{CN}-\mathrm{CE}$ was stronger than $125 \mathrm{mg} / \mathrm{kg}$ free $\mathrm{CE}$ for both effects; a lower dose of $\mathrm{CN}-\mathrm{CE}$, relative to free CE, can exert the same effects. ${ }^{44}$

Quercetin (QU) is a natural flavonoid that has pharmacological properties, such as anti-inflammatory, antitumor, antiviral, inhibitory of cataracts in diabetics, antihistamine (anti-allergic), cardiovascular, antioxidant, and hepatoprotective effects. QU is present in fruits, vegetables, herbs, and related products, eg, apples, onions, Ginkgo biloba (Ginkgoaceae), and red wine. To evaluate the antioxidant effects of pure quercetin and QU incorporated in nanoparticles, Wu et al developed a nanoprecipitation technique using Eudragit $^{\circledR}$ E (Evonik Industries, Essen, Germany) (EE) and polyvinyl alcohol (PVA), alongside the flavonoid quercetin (QUEN). The system was prepared using a 1:10:10 weight ratio of QU to EE to PVA because the yield was better, and the encapsulation efficiency was greater than 99\%. Relative to di(phenyl)-(2,4,6-trinitrophenyl)iminoazanium (DPPH) scavenging, anti-superoxide formation, superoxide anion scavenging, and anti-lipid peroxidation activities, QUEN was more effective than QU. ${ }^{45}$

Camptothecin (CPT) is a natural plant alkaloid extracted from Camptotheca acuminata Decne. (Cornaceae), and has been demonstrated to be a potent anticancer drug, targeting intracellular topoisomerase. However, due to its low water solubility and unstable lactone ring, clinical use is not viable. Min et al developed nanoparticles based on hydrophobically modified glycol chitosan (HGC) as a delivery system. A dialysis method was used to prepare camptothecinencapsulated nanoparticles (CPT-HGC); the loading efficiency exceeded $80 \%$. The hydrophobic core of the HGC nanoparticle protected the crucial lactone ring from hydrolysis under physiological conditions. To verify antitumoral activity of the nanoparticles, a subcutaneous tumor was established, by inoculating MDA-MB-231 human breast cancer cells in the back of a mouse. After intravenous (iv) injection of CPT-HGC, at $10 \mathrm{mg} / \mathrm{kg}$ and $30 \mathrm{mg} / \mathrm{kg}$, tumor growth was significantly inhibited, relative to free CPT (30 mg/kg). The strong antitumoral activity of CPT-HGC was most likely related to prolonged blood circulation, and high accumulation in tumors, as confirmed by near infrared study. ${ }^{46}$

Yen et al developed a naringenin- (NAR) loaded nanoparticles system (NARN), using a nanoprecipitation technique, to improve restricted bioavailability and increase hepatoprotective effects in vivo, after oral administration of NAR. The nanoparticle delivery system was successfully developed using Eudragit (E) and PVA as carriers. Carbon tetrachloride was used to induce hepatotoxicity in male Wistar albino rats of weight 180-220 g, which were randomly divided into four groups of five rats each. For the oral administration of drugs, one group of rats was treated with a NAR suspension in distilled water with Tween ${ }^{\circledR} 20$ (1\% ratio, by volume [v/v]), at $100 \mathrm{mg} / \mathrm{kg}$ per day; another group was treated with NARN at $100 \mathrm{mg} / \mathrm{kg}$ per day. Both treatments were administered, by gavage, for three consecutive days. Examining hepatoprotective effects, NARN protected more of the liver; the NAR group displayed considerable reduction in liver function index and lipid peroxidation, as well as a substantial increase in the levels of antioxidant enzymes. Moreover, NARN significantly inhibited the activation of caspase-3, caspase-8, and caspase-9 signaling, whereas NAR only noticeably inhibited caspase- 3 and caspase- $9 .{ }^{47}$

The ethanolic extract of Polygala senega (Polygalaceae) (EEPS) is used as an expectorant to treat cough, sore throat, bronchitis, and asthma, and as an antihypoglycemic agent. $P$. senega has poor water solubility, preventing aqueous dispersion, and restricting its potential, due to its diminished bioavailability. ${ }^{48}$ EEPS was encapsulated by employing biodegradable PLGA. Subsequently, the anticancer effects of EEPS, and the nanoencapsulated form (NEEPS), were evaluated against lung cancer cell line A549. EEPS and NEEPS induced apoptosis of A549 cells, which was associated with decreased expression of survivin and proliferating cell nuclear antigen (PCNA) mRNA, and increased expression of caspase-3 and p53 mRNAs, in A549 cells. The anticancer potential of the NEEPS formulation surpassed that of EEPS alone. ${ }^{49}$

\section{Solid lipid nanoparticles and nanostructured lipid carriers}

Solid lipid nanoparticles (SLNs) are colloidal carrier systems, developed in the early 1990s, that combine the advantages of other colloidal systems (such as emulsions, liposomes, and polymeric nanoparticles) for drug delivery, while avoiding, or minimizing, some of their drawbacks. ${ }^{50}$ SLNs have higher physicochemical stability, and offer better protection against degradation of labile drugs; they also can be easily produced on a large scale..$^{30,51,52}$

SLNs are colloidal particles containing highly purified triglycerides, composed mainly of lipids that are solid at room temperature. These structures are produced from solid 
lipids, or mixtures thereof, and stabilized by surfactants. ${ }^{53}$ The matrix of the lipid particle is solid; it can protect drug molecules against chemical degradation. However, when the system is produced, crystallization occurs, resulting in low encapsulation efficiency and drug release. ${ }^{30}$ Adding a liquid lipid (oil) to an oil/water emulsion containing a solid lipid, or mixture of solid lipids, promotes the formation of SLNs. ${ }^{51}$ Due to their small size $(50-1,000 \mathrm{~nm})$ and biocompatibility, SLNs may be used in the pharmaceutical field for various routes of administration, such as oral, parenteral, and percutaneous. ${ }^{52}$

Nanostructured lipid carriers (NLCs) improve the efficiency of encapsulation and minimize the expulsion of active particles during encapsulation. ${ }^{54}$ NLCs are second-generation systems, and are attracting attention as alternative vehicles for colloidal drugs. These systems contain a mixture of lipid and solid phases that forms a disorganized liquid lipid matrix, which accommodates active substances. ${ }^{30}$ Some examples of lipids used in the solid phase are stearic acid, glyceryl dilaurate, hydrine, glyceryl monostearate, and cetyl alcohol. Examples of the liquid phase include oleic acid, glyceryl monodicaprylate, and caprylic/capric acid. In most cases, approximately $5 \%$ of the drug (by weight) is incorporated in the initial precursor mixture for NLCs, resulting in drug loading efficiency of approximately $3 \%$ to $4 \%$ (whereas typical encapsulation efficiency is approximately $70 \%) .{ }^{55}$ Several routes may be used to administer these formulations: oral, pulmonary, intravenous, and dermal. The latter is advantageous, because the films form occlusions, there is a controlled release profile, and the formulation is biodegradable and relatively nontoxic. Furthermore, the small size of the two particles ensures contact with the stratum corneum, facilitating increased penetration of the drug into the skin. ${ }^{30}$

There are several methods used to produce SLNs and NLCs, including high-pressure homogenization, emulsification-sonication, microemulsion and solvent emulsification-evaporation techniques. For hot high-pressure homogenization (HPH), the lipid is melted, and the drug is dissolved homogeneously in the molten lipid. Then, a hot aqueous solution of surfactant is added to the molten druglipid mixture, and homogeneously dispersed (pre-emulsion) using a high shear mixing device. Afterwards, the hot preemulsion is subjected to high pressure homogenization; this process is repeated until the desired average particle size is obtained. Then, the nanoemulsion is cooled to room temperature. During cooling, lipid droplets in the nanoemulsion recrystallize, forming lipid nanoparticles in the solid matrix. The process of cold HPH is similar to hot HPH: the lipid is melted, and the drug is homogeneously dissolved in the molten lipid. Then, the drug-lipid melt is rapidly cooled, using liquid nitrogen or dry ice, and subsequently milled to form microparticles. The microparticles are suspended in a cold aqueous surfactant solution, and homogenized at low temperatures to form lipid nanoparticles. This technique is used for hydrophilic or thermolabile drugs, to prevent drug degradation. The emulsification-sonification method is similar to the first portion of HPH. After the drug is dissolved in melted solid lipid, a hot aqueous surfactant solution is added to the melt, and homogeneously dispersed using a high shear mixing device. The coarse, hot oil-in-water emulsion is ultrasonicated using a probe sonicator until a nanoemulsion of the desired size forms. Finally, lipid nanoparticles are obtained by allowing the hot nanoemulsion to cool to room temperature. The microemulsion method utilizes a drug dissolved in a molten solid lipid. The aqueous surfactant/cosurfactant solution is added to the lipid with mild agitation to obtain transparent microemulsion. Afterwards, the microemulsion is dispersed in cold water $\left(2^{\circ} \mathrm{C}-10^{\circ} \mathrm{C}\right)$ with mild agitation, where it breaks into ultrafine nanoemulsion droplets, which immediately crystallize to form SLNs. In the solvent emulsification-evaporation method, the lipid is dissolved in a water-immiscible organic solvent (eg, cyclohexane and chloroform) and emulsified, in an aqueous phase containing surfactants, with continuous stirring. The organic solvent evaporates during emulsification, precipitating the lipids. ${ }^{56}$

Quercetin is a natural flavonoid that becomes more effective when incorporated into lipid carriers. Li et al incorporated QU, which is poorly soluble in aqueous media, in SLNs (QU-SLN) using the emulsification-solidification method at low temperatures. The desired amounts of QU, glyceryl monostearate, and soy lecithin were mixed with the solvent (chloroform and acetone in 1:1 ratio v/v). The SLNs were spherical, with an average size of $155.3 \pm 22.1 \mathrm{~nm}$, falling into the nanoscale range $(20-500 \mathrm{~nm})$. QU-SLN exhibited controlled release in vitro. In the in vivo experiments, the bioavailability of QU-SLN was more than five times greater, and demonstrated enhanced absorption in the intestine (rather than the stomach), compared to free QU. ${ }^{57}$

In another study, Guo et al incorporated QU into NLCs (QU-NLCs), to evaluate the formulation's potential as a topical delivery system. The formulation contained QU, glyceryl monostearate, stearic acid, and soy lecithin, and was prepared using the emulsion evaporation-solidification method, at low temperatures. The nanoparticles were spherically shaped, had an average particle size of $215.2 \mathrm{~nm}$, 
and an average entrapment efficiency of $89.95 \% \pm 0.16 \%$. Therefore, the incorporation was efficient; it could promote permeation of QU, increase the amount of QU retained in epidermis and dermis, and enhance the antioxidant and anti-inflammatory effects exerted by the flavonoid. Studies of the effects of QU-NLCs on the skin's surface confirmed that they could weaken the barrier function of the stratum corneum, and thus facilitate drug permeation through the skin. In vivo anti-inflammatory assays indicated that QUNLCs stopped ear edema, induced in rats by xylene. In vitro studies probing into superoxide anion radical scavenging activity confirmed that QU's complete functional architecture was retained after nanoencapsulation. This study provided additional evidence that NLCs have a targeting capability, a prolonged release, and a great potential for dermal delivery. ${ }^{58}$

Bose and Michniak-Kohn evaluated whether nanoscale lipids could deliver QU topically. The systems were prepared by replacing a portion of the solid lipid (glyceryl dibehenate) (Compritol ${ }^{\circledR} 888$ ATO) in the SLN formulation with a liquid lipid (oleic acid), to produce QU-NLCs using the probe ultrasonication method. This study evaluated the stability of these nanosystems for 14 weeks, at $2^{\circ} \mathrm{C}-8^{\circ} \mathrm{C}$. The average size of the NLCs was $282 \mathrm{~nm}$, indicating that the structures had excellent stability. TEM measurements revealed spherical particles. The NLC system showed the largest improvement during topical delivery of QU, which was expressed using the amount of flavonoid that was maintained in full-thickness human skin, compared against a control formulation with a similar composition and a particle size in the micrometer range. This study illustrated that NLCs are viable for improved topical deliveries of QU. ${ }^{59}$

A study performed by Kakkar et al sought to improve the oral bioavailability of curcumin by incorporating it into SLNs composed of soy lecithin. The microemulsification method was used to prepare this formulation. The SLN par-

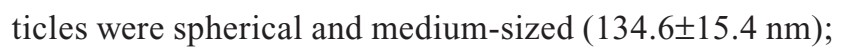
drug entrapment efficiency was $92.33 \% \pm 1.63 \%$. Studies of stability revealed that SLNs loaded with curcumin (C-SLN) showed only a decrease of approximately $9 \%$ in efficiency of incorporation, after 12 months of storage at $5^{\circ} \mathrm{C} \pm 3^{\circ} \mathrm{C}$, indicating that the C-SLNs were stable. Moreover, C-SLN exhibited prolonged drug release in vitro. In vivo pharmacokinetic studies revealed that after orally administered C-SLN (50 mg/kg, $25 \mathrm{mg} / \mathrm{kg}, 12.5 \mathrm{mg} / \mathrm{kg}$, and $1 \mathrm{mg} / \mathrm{kg}$ ), a significant improvement in oral bioavailability was achieved, compared to free CU (by 39, 32, 59, and 155 times at $50 \mathrm{mg} / \mathrm{kg}, 25 \mathrm{mg} / \mathrm{kg}, 12.5 \mathrm{mg} / \mathrm{kg}$, and $1 \mathrm{mg} / \mathrm{kg}$ doses, respectively). ${ }^{60}$

Mei et al incorporated triptolide (TP) into SLNs (TPSLN) consisting of tristearin glyceride and stearic acid, to improve solubility and absorption into skin. TP is a purified compound made from a traditional Chinese medicine that was isolated from the shrublike vine, Tripterygium wilfordii Hook. F (Celastraceae). Studies have shown that vine extracts are effective for the treatment of certain diseases, including inflammatory and autoimmune diseases, such as rheumatoid arthritis. The results revealed that TP-SLN increased the acute anti-inflammatory activity, because TP penetrated further into the skin. ${ }^{61}$

Martins et al developed and validated a simple high performance liquid chromatography method to determine the content of camptothecin (CP) in various organs in rats, after administration of CP via SLN. Their formulations utilized cetyl palmitate as the lipid, and polysorbate 80 as the surfactant, at $5 \%$ ratio by weight $(\mathrm{w} / \mathrm{w})$ and $2 \%(\mathrm{w} / \mathrm{w})$. A Prominence UFLC system (Shimadzu Scientific, Kyoto, Japan), equipped with two pumps (LC-20AD; Shimadzu), an autosampler (SIL-20AC; Shimadzu), and a column oven (CTO-20AC; Shimadzu), was used for every chromatographic analysis. The optimized method utilized a binary gradient mobile phase with $1 \%(\mathrm{v} / \mathrm{v})$ triethylamine buffer at pH 5.5 as mobile phase $\mathrm{A}$, and acetonitrile as mobile phase $B$. The flow rate was $1.2 \mathrm{~mL} / \mathrm{min}$, and the injection volume was $10 \mu \mathrm{L}$. The eluted peaks were monitored at the excitation and emission wavelengths of $360 \mathrm{~nm}$ and $440 \mathrm{~nm}$, respectively. This method was reliable, precise, and accurate for determining the amount of $\mathrm{CP}$ in samples from organs of rats treated with $\mathrm{CP}$ in suspension, or $\mathrm{CP}$ incorporated in SLNs. ${ }^{62}$

Tiyaboonchai et al incorporated curcuminoids into SLNs, to characterize factors that might affect the processing characteristics and storage stability of the system. The water phase consisted of $0.1 \%(\mathrm{w} / \mathrm{w})$ curcuminoid extract, 5\%-15\% (w/w) poloxamer $188,5 \%-15 \%(\mathrm{w} / \mathrm{w})$ dioctyl sodium sulfosuccinate, 5\%-20\% (w/w) ethanol, and deionized water, added to $100 \%(\mathrm{w} / \mathrm{w})$. The oil phase contained 5\%-12.5\% (w/w) stearic acid and 4\% (w/w) glyceryl monostearate. Preparation was performed using the microemulsion method at moderate temperatures. The particles were spherical, of $450 \mathrm{~nm}$ average size, and had a $0.4 \%-70 \%(\mathrm{w} / \mathrm{w})$ polydispersity index. After being stored in the absence of sunlight for 6 months, the remaining percentages of curcumin, demethoxycurcumin, and bisdemethoxycurcumin were $91 \%, 96 \%$, and $88 \%$, respectively. 
Thus, SLNs improved the stability of curcuminoids in the absence of light. ${ }^{63}$

\section{Liquid crystalline systems}

Liquid crystals are a distinct phase of condensed structures that rest in a state intermediate between a crystalline solid and an isotropic liquid; they may be ordered or disordered, as indicated by their ease of efflux. States of matter between solids and liquids are mesophases, which may be cubic or hexagonal in LCs. LCs are categorized according to two general provisions: thermotropic liquid crystals (TLCs) and lyotropic liquid crystals (LLCs). ${ }^{64,65}$

TLCs have temperature-dependent liquid-crystalline phases, and a specific temperature at which the liquid crystal becomes an isotropic liquid. Their main constituent is the molecule that forms the mesophase. LLCs possess functional unit micelles, which are aggregates composed of amphiphilic molecules. Amphiphiles have a small polar (hydrophilic) part and a large (hydrophobic) apolar tail. Mesophase formation is dependent on concentration, solvent, and temperature; under certain conditions, micelles can self-organize, generating structures of great complexity. ${ }^{66-68}$

Liquid crystalline mesophases are identified using measurements of their optical isotropy via polarized light microscopy, electron microscopy with cryofracture, neutron diffraction, X-ray scattering at low angle (SAXS) and neutron scattering at low angles (SANS). ${ }^{64,69,70}$

For pharmaceutical applications, LCs have stable and favorable properties for chaperoning biologically active principles that are normally inactive, due to unfavorable interactions with lipid membranes at the active site, or degradation processes. LCs effectively promote an interaction between the drug and a specific target site that was previously not accessible, and optimize contact time at the site. LC components promote interactions between the active molecules and cell membranes, facilitating entry into the cell, promoting pharmacological action. ${ }^{71-73}$

Development of a drug delivery system that is reliable, effective, and safe for treatments against diseases is a goal for various researchers. Furthermore, drug delivery systems should also package drugs such that their distribution is even, given a selected administration route, prioritizing the best drug-receptor interaction and the reduction of harmful effects. Therefore, finding a system that meets all of these needs would be extremely valuable. LC-based drug delivery systems are potential candidates. ${ }^{74,75}$

Nanotechnology researchers seek to implement new technological approaches to extend the benefits presented by drug delivery systems. Consequently, decreasing toxic effects and/or cumulative effects has met with growing interest in recent years. In addition, a slight increase in the use of natural products has been observed within nanostructured systems incorporating drugs, because medicinal products obtained this way have some advantages over drugs derived from synthetic sources. The natural compounds have fewer side effects (when comparing their toxicological and pharmacological activities) than those obtained from industrial sources. ${ }^{76,77}$

One of the most useful types of plant component for developing LC systems is vegetable oils, because they have favorable properties, including low viscosity and low molecular weight. Vegetable oils are used because they produce low-occlusion, compared to mineral oils, allowing a greater capacity for dermal penetration, and permitting increased loading of therapeutic agents. ${ }^{78,79}$

Andrade et al evaluated silicone as a surfactant for forming LC phases in a system containing the essential oil, andiroba (Carapa guyanensis Aubl.) (Meliaceae), cetearyl alcohol, dicetyl phosphate, and a ceteth-10 phosphate-like oily phase. To prepare the aqueous phase, distilled water and PEG-12 Dimethicone was used. Using the herbal compound did not influence any important LC parameters, such as the viscosity of the formulation, or the favorable rheological stability. ${ }^{80}$

Studies have detailed the use of products from natural sources during the development of nanostructured systems containing LCs. Masson et al evaluated the influence of peach essential oil (Prunus persica) (Rosaceae) during the formation of LCs in oil in water emulsions $(\mathrm{o} / \mathrm{w})$ containing a self-emulsifying base. The study demonstrated numerous benefits of incorporating this essential oil, including improved physical stability. The results of these studies are extremely important because adding the essential oil as a constituent of the oil phase did not preclude the formation of LCs. ${ }^{76}$

Morais et al pursued the development of LC systems with annatto oil from Bixa orellana (Bixaceae) seed, using the hydrophilic/lipophilic balance method (HLB). The formulations were composed of annatto oil (oil phase), distilled water (aqueous phase), and oleth-20 (HLB value: 15.3) as the surfactant. The authors observed that was possible to construct LC systems using annatto oil as the oil phase. ${ }^{81}$

Santos et al revealed the formation of liquid crystals from marigold oil (Calendula officinalis) (Asteraceae), distilled water, and nonionic surfactants. They employed the HLB method to assess the components' influence on the formation of LCs. Different ethoxylated fat alcohols were used, 
with varied lengths of carbon chain, and moles of ethylene oxide per molecule of the surfactant, Ceteth-2 (HLB: 5.3), Ceteth-10 (HLB: 11.0), Steareth-2 (HLB: 4.7), Steareth-20 (HLB: 15.3), Ceteareth-5 (HLB: 9.2), and Ceteareth-20 (HLB: 15.7). The authors concluded that the proposed formulations were stable, because the required HLB value for the formulations was 6.0, which makes vegetable oil promising for forming LC phases. Under microscopic analysis, no significant differences were noted in the structures of the LCs in any of the proposed formulations. However, there were variations in rheological behavior, due to variation in the surfactants. ${ }^{82}$

Santos and Rocha-Filho developed a formulation for previously-identified lamellar LC phases, to ascertain the influence of the length of carbon chain and the number of ethylene oxide units on the stability of a nonionic emulsion, using marigold oil from seeds and flowers of C. officinalis. The system contained marigold oil, distilled water, and several polyoxyethylene alkyl or stearyl ethers (surfactants): polyoxyethylene cetyl ether (Ceteth-2; HLB: 5.1), polyoxyethylene stearyl ether (Steareth-2; HLB: 4.7), polyoxyethylene cetyl ether (Ceteth-10; HLB: 11.0), and polyoxyethylene stearyl ether (Steareth-20; HLB: 15.3). The authors noted that using oil in the formulation is essential for forming the LC phase, and identified the carbon chain as being responsible for the observed stability. The authors concluded that the number of ethylene oxide moieties was not as significant as the carbon chain. ${ }^{83}$

Following the trend of using natural compounds in systems containing nanostructured LCs, Santos et al proposed using vegetable oils from plants native to Brazil during evaluations for the formation of lamellar LC crystalline phases. The following vegetable oils were used: andiroba (Carapa guyanensis) Aubl (Meliaceae), apricot (Prunus armeniaca) (Rosaceae), avocado (Persea americana Mill) (Lauraceae), Brazil nut (Bertholletia excelsa Bonpl) (Lecythidaceae), Buriti (Mauritia flexuosa) (Arecaceae), cupuassu (Theobroma grandiflorum Willd. ex Spreng. Schum) (Sterculiaceae), marigold (C. officinalis) (Asteraceae), passion fruit (Passiflora edulis Sims.) (Passifloraceae), and pequi (Caryocar brasiliense Camb.) (Caryocaraceae). Additionally, mineral oil and liquid paraffin were used for comparison. Distilled water was used as the aqueous phase. The surfactants were ethoxylated fatty acids: polyoxyethylene stearyl ether (Steareth-2; HLB: 4.7) and polyoxyethylene cetyl stearyl ether (Ceteareth-5; HLB: 9.2). All the formulations were stable, except the sample made with mineral oil. The authors demonstrated that mixing different surfactants with different
HLB loads did not affect the formation of nanostructured LCs containing a natural oil phase. ${ }^{84}$

In recent years, products from natural sources have been used in the production of nanostructured systems for drug delivery or in the preparation of high-tech cosmetics. However, there are no reports of incorporating these compounds in LCs for medicinal purposes, which encourages the scientific community to turn to the development of new LC systems as drug vehicles, to promote important, indispensable factors, such as bioavailability and the chemical/physical stability of herbal compounds.

\section{Liposomes and microemulsions}

Liposomes are microscopic vesicles composed of one or more concentric lipid bilayers, separated by an aqueous medium. Hydrophilic substances are encapsulated in the aqueous compartment, while adsorbed lipophiles are inserted into the membrane. Alternatively, both types of substance can be encapsulated. These vesicles consist primarily of phospholipids (synthetic or natural), sterols, and an antioxidant. ${ }^{85,86}$

Liposomes are classified according to their size, number of lamellae, and surface charge. As to surface charge, liposomes are classified as anionic, cationic, or neutral. With regards to form, size, and number of lamellae, liposomes can be classified as oligo-, uni- or multilamellar, and small, large, or giant. Unilamellar liposomes (ULs) contain a single bilayer and are classified in various size ranges: small unilamellar liposomes (SUVs), with diameters of approximately 25-100 nm; large unilamellar liposomes, with diameters of $100 \mathrm{~nm}$ to $1 \mu \mathrm{m}$; and giant unilamellar liposome, with diameters greater than $1 \mu \mathrm{m}$, which reach sizes in the tens of microns (comparable to eukaryotic cell size). Multilamellar liposomes (MLVs) consist of many concentric lamellae, exhibiting an onion-like structure. ULs are often found in dilute solutions of surfactants, whereas MLVs are found in more concentrated systems. ${ }^{85,86}$

Andrade et al developed, characterized, and investigated the antitumoral activity of liposomes containing Cratylia mollis lectin (Cra) purified from seeds of Cratylia mollis Mart (Fabaceae) (Camaratu bean) against Sarcoma-180 in Swiss mice. Cra, which has immunostimulatory action, was used in the protein supplementation of the animals' diet. In vitro, this action assists in the production of immunoglobulins in human B lymphocytes cultures and causes antibacterial activity. Systems with positively charged surfaces were developed using soybean-phosphatidylcholine, cholesterol, and stearylamine in the molar ratio: 7:2:1 (36 $\mu \mathrm{mol}$ lipids per $10 \mu \mathrm{L} 0.2 \mathrm{M}$ phosphate buffer solution; $\mathrm{pH} 7.4$ ). The animals 
were treated with Cra-loaded liposomes; histopathological analyses of the tumor, liver, and kidneys were carried out after treatment. The Cra-loaded liposomes inhibited tumor by $71 \%$, whereas Cra solution inhibited the tumor by only $43 \%$; liposome-encapsulated Cra improved antitumoral activity by $28 \%$. The liver and kidney were protected from lymphocyte infiltration when Cra was incorporated in the liposomes; reduced necrosis was also observed in the treated tumors. This system has two advantages: reduced tissue toxicity and increased antitumor activity. ${ }^{87}$

Priprem et al investigated the anxiolytic and cognitive activities of QU in male Wistar rats. The researchers developed liposomes for intranasal administration, composed of a mixture of egg phosphatidylcholine, cholesterol and QU (in $2: 1: 1$ ratio). The mean diameter of the liposomes was $200 \mathrm{~nm}$; they had a negative surface charge. The range of encapsulation efficiency was between $60 \%-80 \%$. A suspension of QU dispersed in a solution containing $50 \%$ polyethylene glycol in water was freshly prepared for oral administration (300 mg of QU per kg body weight), and was compared to orally, and intranasally, delivered QU liposomes (0.5 mg QU in $20 \mu \mathrm{L}$; dose: $20 \mu \mathrm{g}$ ). QU liposomes were administered orally, or directly into the right nasal cavity of each rat. The same dose was given repeatedly to the same rat at the same time each day. To evaluate anxiety and cognitive effects, using the elevated plus maze and the Morris water maze, respectively, the rats had their behavior evaluated after single and repeated daily doses for 7 days, 14 days, 21 days, and 28 days. Both QU and oral QU liposomes demonstrated an improvement in cognitive and anxiolytic effects. However, intranasal QU liposomes displayed better results faster, and at a lower dose than the other treatments. The best cognitive and anxiolytic effects for intranasal QU liposomes may be attributed to the alteration of various neurotransmitters, including gamma aminobutyric acid and serotonin, respectively. ${ }^{88}$

Silymarin, a known standardized extract obtained from seeds of Silybum marianum (Compositae), is used to treat liver diseases of various origins. However, it has low oral bioavailability, and it is poorly absorbed (20\%-50\%) from the gastrointestinal tract. Therefore, El-Samaligy et al studied silymarin hybrid liposomes for buccal administration. Silymarin induces a dose-dependent hepatoprotective activity against carbon tetrachloride-induced oxidative stress in albino rats. This bioassay provided useful data for evaluating the efficiency of the buccal liposomal formula relative to the orally administered silymarin suspension. Silymarin hybrid liposomes were prepared using the reverse evaporation technique, composed of lecithin (L), cholesterol (Ch), stearylamine (AS), and Tween 20 (T20) in the molar ratio 9:1:1:0.5. Liver studies were conducted using male albino rats weighing $180-220 \mathrm{~g}$. The rats received $0.25 \mathrm{~mL}$ of carbon tetrachloride in liquid paraffin $(1: 1, \mathrm{v} / \mathrm{v})$ per $100 \mathrm{~g}$ body weight, intraperitoneally (ip), to induce hepatic damage. The degree of protection was measured using biochemical parameters, such as serum glutamic oxalacetate transaminase and serum glutamic pyruvate transaminase. The silymarin hybrid liposome was evaluated, upon buccal administration, for its hepatoprotective activity. It produced a significant decrease in both transaminase levels, when challenged with carbon tetrachloride (ip), relative to the orally administered silymarin suspension. ${ }^{89}$

Breviscapine (bre) is a flavonoid isolated from the traditional Chinese medicinal herb Erigeron breviscapus (vant.) Hand. Mazz (Compositae), which has proven to be effective in protecting the brain against ischemic damage, via an unknown mechanism. To prolong the duration of time the drug remains in circulation, reduce the frequency of injection, and subsequently improve patient compliance, multivesicular liposomes (MVLs) (DepoFoam ${ }^{\circledR}$ ) were synthesized as a sustained delivery system for bre (bre-MVL). In vitro and in vivo pharmacokinetics were investigated, and compared to traditional liposomes containing bre (bre-TLs). Bre-MVLs were prepared using a double emulsification process, as described by Kim et $\mathrm{al}^{90}$ and Katre et $\mathrm{al}^{91}$, using phosphatidylcholine, phosphatidylglycerol, cholesterol, and triolein or tricaprylin. Both in vitro and in vivo, bre-MVL significantly prolonged sustained delivery, relative to bre-TL. The mean residence time obtained from the pharmacokinetic study of bre-MVL was approximately 16.6 times and 5.04 times longer than that of bre solution and bre-TL, respectively. In vivo, a duration of 4-5 days was achieved by bre-MVL. In conclusion, as a lipid depot delivery system, MVLs may be successfully utilized for sustained delivery of breviscapine..$^{92}$

To overcome difficulties of insolubility and instability with the active lactone form of camptothecin (CPT), a potent antitumor agent, Watanabe et al incorporated CPT, isolated from the Chinese plant Camptotheca acuminata Decne. (Nyssaceae), into PEGylated liposomes. CPT was incorporated into liposomes by adding 3,5-bis (dodecyloxy) benzoic (PO)polyethylene glycol-containing liposomes, and by coating the surface of the liposomes with human serum albumin (HSA-DB-L). Antitumor activity was evaluated against mice bearing colon adenocarcinoma 28 . The treatment of female mice with colon adenocarcinoma started two weeks after solid tumor transplantation by iv injection into the lateral tail vein. A CPT solution was used as a single injection at $1.5 \mathrm{mg} / \mathrm{kg}$ 
body weight, and HSA-DB-L (eg, $2.5 \mathrm{mg}$ CPT and $25 \mathrm{mg}$ total $\mathrm{lipid} / \mathrm{mL}$ ) was given as one injection at $10 \mathrm{mg} / \mathrm{kg}$ or $15 \mathrm{mg} /$ $\mathrm{kg}$, and another at $10 \mathrm{mg} / \mathrm{kg}$. The tumor growth in mice was inhibited after a single iv injection of HSA-DB-L at $15 \mathrm{mg} /$ $\mathrm{kg}$. No significant body weight loss, but a significant increase in the accumulation of CPT in tumor tissue was observed (9.6 times greater); the accumulation was more efficient than with CPT solution, at 24 hours after iv injection. These findings suggest that HSA-DB-L can increase the stability and enhance the antitumor effect of CPT..$^{93}$

Herpes simplex virus is one of the most common viral diseases in humans. H. simplex 1 (HSV-1) and H. simplex 2 (HSV-2) have been distinguished by clinical manifestations, and biological and serological criteria. Several drugs have been used to treat these infections, but the larger problem is, currently, strains that are resistant to these drugs. In addition, there are cases of toxicity, particularly in immunocompromised patients. To find less toxic antiviral agents, Sinico et al investigated in vitro the effect of liposomal inclusion of the antiherpetically-active essential oil, Artemisia arborescens L. (Asteraceae). Positively charged MLVs and SUVs were prepared using the film method with sonication, and were obtained from hydrogenated and non-hydrogenated soy phosphatidylcholine, respectively. The antiviral activity of free versus liposomal $A$. arborescens essential oil (EO), against HSV-1 virus, was evaluated. Both MLV and SUV showed a good capability to entrap EO (60\% and $74 \%$, respectively). When EO was entrapped in MLV, a significant increase in the antiviral activity of $A$. arborescens was observed, relative to the free oil..$^{29}$

The term microemulsion (ME) was first introduced by Hoar and Schulman in 1943, to define a fluid system obtained by titration, composed of a simple emulsion with a medium chain alcohol, such as hexanol or pentanol; initially semitransparent, and titrated until clear. ${ }^{94}$

MEs are transparent emulsions, in which an oil is dispersed in an aqueous medium (or vice-versa) containing a surfactant, with or without a suitable cosurfactant. These conditions generate a thermodynamically stable system, with droplets of the internal phase measuring on the nanoscale $(\mathrm{nm})$. Active substances may be carried in the microemulsions when they are solubilized in the oil, or the aqueous phases. $^{95,96}$

MEs are reservoir systems, once the drug is separated from the dissolution medium through a membrane or interface that must be transposed to control the release into the environment. These systems provide a dimensionally restricted environment with private properties, and are capable of connecting or associating molecules of different groups of drugs, with the purpose of improving their solubility, modular stability, or bioavailability profile. ${ }^{95}$

Another point to be highlighted is the ability of microemulsified systems to improve the solubility and stability of the drugs, aside from providing prolonged action; specifically, targeting for certain tissues or organs of the body, and being able to convey active substances with differing degrees of hydrophilicity/lipophilicity within the same formulation..$^{20,21}$

Triptolide (TP) is a purified compound from a traditional Chinese medicine isolated from the shrublike vine, Tripterygium wilfordii Hook. F (Celastraceae). It exhibits diverse biologic properties, including anti-inflammatory, immunosuppressive, antifertility and antineoplastic activities. However, its clinical use is restricted, due to its poor water solubility and some toxic effects. To improve these disadvantages, a microemulsion (ME) system was developed by Mei et al. ${ }^{61}$ The researchers developed, characterized, and evaluated in vitro the permeation and anti-inflammatory activity of microemulsions associated with TP. The MEs were prepared with water (water phase), isopropyl myristate TP (oil phase) and Tween 80:1,2-propylene glycol (surfactant: co-surfactant). The formulation that contained $0.025 \%$ TP, $40 \%$ isopropyl myristate TP, and 50\% Tween 80 in:1,2-propylene glycol $(5: 1, \mathrm{v} / \mathrm{v})$ revealed the highest permeation profile. Carrageenan-induced rat paw edema was significantly suppressed by the microemulsion incorporating TP. The results shows the highest anti-inflammatory effects by TP incorporated in microemulsions. ${ }^{61}$

Extracts from the fruit pulp of Syagrus romanzoffiana (Cham.) Glassman (Arecaceae) were incorporated into o/w nanoemulsions prepared using the phase inversion method, with squalane as the oil phase, and a pair of oleic alcohol ethoxylated surfactants as non-ionic surfactants (Oleth-3: oleyl alcohol 3OE and oleic alcohol 20OE). Mezadri evaluated the antioxidant activity of these extracts using the DPPH reagent and noticed a good antioxidant activity, which was very important for determining the concentration of these extracts to be used in nanoemulsions. The addition of extracts of $S$. romanzoffiana in formulations did not alter the characteristics obtained. This was the first study involving the development of nanoemulsions that contain these extracts. Further studies should be conducted, to better understand other pharmacological activities involved when using these materials. ${ }^{97}$

\section{New approaches and challenges}

Nanosized drug delivery systems for herbal drugs can potentially enhance the biological activity and overcome problems 
associated with plant medicines. However, significant challenges remain for implementation of clinically viable therapies in this field. Trials of novel methods to control the interactions of nanomaterials with biological systems represent some of the current challenges to translating these technologies to therapies. New challenges in the development of nanotechnology-based drug delivery systems include: the feasibility of scale-up processes that bring innovative therapeutic techniques to the market quickly, and the possibility of obtaining multifunctional systems to fulfill several biological and therapeutic requirements. Some additional new challenges include probing the targeting efficiency of nanoparticles, and satisfying international standards for their toxicology and biocompatibility.

\section{Disclosure}

The authors report that they have no conflicts of interest in this work.

\section{References}

1. Ferreira VF, Pinto AC. A fitoterapia no mundo atual [Phytotherapy in the world today]. Quim Nova. 2010;33(9):1829. Portuguese.

2. Souza-Moreira TM, Salgado HRN, Pietro RCLR. O Brasil no contexto de controle de qualidade de plantas medicinais [Brazil in the context of quality control of medicinal plants]. Rev Bras Farmacog. 2010;20(3):432-440. Portuguese.

3. Pires AM, Araújo PS. Percepção de risco e conceitos sobre plantas medicinais, fitoterápicos e medicamentos alopáticos entre gestantes [Risk perception and concepts about medicinal plants, herbal and allopathic medicines among pregnant women]. RBSP. 2011;35(2):320-333. Portuguese.

4. Badke MR, Budó MLD, Silva FM, Ressel LB. Plantas Medicinais: o saber sustentado na prática do cotidiano popular [Medicinal Plants: popular knowledge in sustained daily practice]. Esc Anna Nery. 2011;15(1):132-139. Portuguese.

5. Costa EMMB, Barbosa AS, Arruda TA, et al. Estudo in vitro da ação antimicrobiana de extratos de plantas contra Enterococcus faecalis [In vitro antimicrobial activity of plant extracts against Enterococcus faecalis]. J Bras Patol Med Lab. 2010;46(3):175-180. Portuguese.

6. Verma S, Singh SP. Current and future status of herbal medicines. Vet World. 2008;1(11):347-350.

7. Bresolin TMB, Filho VC. Fármacos e medicamentos: uma abordagem multidisciplinar [Drugs and medicines: a multidisciplinary approach]. São Paulo: Santos; 2010. Portuguese.

8. Mazzolin LP, Nasser ALM, Moraes TM, et al. Qualea parviflora Mart.: an integrative study to validate the gastroprotective, antidiarrheal, antihemorragic and mutagenic action. J Ethnopharmacol. 2010;127(2): 508-514.

9. Kluczynik CE, Souza JH, Palmeira JD, et al. Perfil de sensibilidade de Salmonella sp. de ambiente aquático a antimicrobianos comerciais e a extratos hidroalcoólicos de plantas medicinais [Sensitivity profile of Salmonella sp. aquatic environment antimicrobial and commercial extracts of medicinal plants]. Rev Bras Anal Clin. 2010;42(2):141-144. Portuguese.

10. Kesarwani K, Gupta R. Bioavailability enhancers of herbal origin: an overview. Asian Pac J Trop Biomed. 2013;3(4):253-266.

11. Holmberg K, Shah DO, Schwager MJ, editors. Handbook of Applied Surface and Colloid Chemistry. Goteborg, Sweden: Wiley; 2002.

12. Ajazuddin SS. Applications of novel drug delivery system for herbal formulations. Fitoterapia. 2010;81(7):680-689.
13. Mainardes RM, Urban MCC, Cinto PO, Chaud MV, Evangelista RC, Gremião MPD. Liposomes and micro/nanoparticles as coloidal carriers for nasal drug delivery. Curr Drug Deliv. 2006;3(3):275-285.

14. Grill AE, Johnston NW, Sadhukha T, Panyam J. A review of select recent patents on novel nanocarriers. Recent Pat Drug Deliv Formul. 2009;3(2):137-142.

15. Venugopal J, Prabhakaran MP, Low S, et al. Continuous nanostructures for the controlled release of drugs. Curr Pharm Des. 2009;15(15):1799-1808.

16. Chorilli M, Brizante AC, Rodrigues CA, Salgado HRN. Aspectos gerais em sistemas transdérmicos de liberação de fármacos [General features of transdermal drug delivery]. Infarma. 2007;88(1):7-13. Portuguese.

17. Baley MM, Berkland CJ. Nanoparticle formulations in pulmonar drug delivery. Med Res Rev. 2009;29(1):196-212.

18. Chen Y, Lin X, Park H, Greever R. Study of artemisin in nanocapsules as anticancer drug delivery system. Nanomedicine. 2009;5(3): 316-322.

19. Pestana KC, Formariz, TP, Franzini CM, et al. Oil-in-water lecithinbased microemulsions as a potential delivery system for amphotericin B. Colloids Surf B Biointerfaces. 2008;66(2):253-259.

20. Cunha ASC Jr, Fialho SL, Carneiro LB, Oréfice F. Microemulsões como veículo de drogas para administração ocular tópica [Microemulsion as a vehicle for drugs in topical ocular administration]. Arq Bras Oftamol. 2003;66(3):385-391. Portuguese.

21. Sintov AC, Shapiro, L. New microemulsion vehicle facilitates percutaneous penetration in vitro and cutaneous drug bioavailability in vivo. J Control Release. 2004;95(2):173-183.

22. Lee RW, Shenoy DB, Sheel R. Micellar nanoparticles: applications for topical and passive transdermal drug delivery. In: Kulkarni VS, editor. Handbook of Non-Invasive Drug Delivery Systems. Burlington, MA: Elsevier Inc; 2010:37-58.

23. Yadav A, Ghune M, Jain DK. Nano-medicine based drug delivery system. J Adv Pharm Educ Res. 2011;1(4):201-213.

24. Singh R, Tiwari S, Tawaniya J. Review on nanotechnology with several aspects. Int J Res Comput Eng Electron. 2013;2(3):1-8.

25. Ghosh V, Saranya S, Mukherjee A, Chandrasekaran N. Antibacterial microemulsion prevents sepsis and triggers healing of wound in wistar rats. Colloids Surf B Biointerfaces. 2013;105:152-157.

26. Rajendran R, Radhai R, Kotresh TM, Csiszar E. Development of antimicrobial cotton fabrics using herb loaded nanoparticles. Carbohydr Polym. 2013;91(2):613-617.

27. Bhattacharya S, Ghosh, AK. Phytosomes: the emerging technology for enhancement of bioavailability of botanicals and nutraceuticals. Int $J$ Aesthetic Antiaging Med. 2009;2(1):87-91.

28. Su YL, Fu ZY, Zhang JY, Wang WM, Wang H, Wang YC. Preparation of Radix salvia nanoparticles. Powder Technol. 2008;184(1):114-121.

29. Sinico C, De Logu A, Lai F, et al. Liposomal incorporation of Artemisia arborescens L. essential oil and in vitro antiviral activity. Eur J Pharm Biopharm. 2005;59(1):161-168.

30. Santos FK, Oyafuso $\mathrm{MH}$, Kiill CP, Gremião MPD, Chorilli M. Nanotechnology-based drug delivery systems for treatment of hyperproliferative skin diseases - a review. Curr Nanosci. 2013;9(1): 159-167.

31. Khuda-Bukhsh AR, Bhattacharyya SS, Paul S, Boujedaini N. Polymeric nanoparticle encapsulation of a naturally occurring plant scopoletin and its effects on human melanoma cell A375. Zhong Xi Yi Jie He Xue Bao. 2010;8(9):853-862.

32. Mainardes RM, Gremião MPD, Evangelista RC. Thermoanalytical study of praziquatel-loaded PLGA nanoparticles. Braz J Pharm Sci. 2006;42(4):523-530.

33. Alexis F, Pridgen E, Molnar LK, Farokhzad OC. Factors affecting the clearance and biodistribution of polymeric nanoparticles. Mol Pharm. 2008;5(4):505-515.

34. Schaffazick SR, Guterres SS, Freitas LL, Pohlmann AR. Caracterização e estabilidade físico-química de sistemas poliméricos nanoparticulados para administração de fármacos [Characterization and physicochemical stability of nanoparticle polymeric systems for drug administration]. Quim Nova. 2003;26(5):726-737. Portuguese. 
35. Kumari A, Yadav SK, Yadav SC. Biodegradable polymeric nanoparticles based drug delivery system. Colloids Surf B. 2010;75(1):1-18.

36. Das J, Das S, Samadder A, Bhadra K, Khuda-Bukhsh AR. Poly (lactideco-glycolide) encapsuled extract of Phytolacca decandra demonstrates better intervention against induced lung adenocarcinoma in mice and on A549 cells. Eur J Pharm Sci. 2012;47(2):313-324.

37. Brewer E, Coleman J, Lowman A. Emerging technologies of polymeric nanoparticles in cancer drug delivery. J Nanomater. 2011;2011(1): 1-10.

38. Bisht S, Feldmann G, Soni S, et al. Polymeric nanoparticle-encapsulated curcumin ("nanocurcumin"): a novel strategy for human cancer therapy. J Nanobiotechnology. 2007;5(3):1-18.

39. Mukerjee A, Vishwanatha JK. Formulation, characterization and evaluation of Curcumin-loaded PLGA nanospheres for cancer therapy. Anticancer Res. 2009;29(10):3867-3876.

40. Bhawana Basniwal RK, Buttar HS, Jain VK, Jain N. Curcumin nanoparticles: preparation, characterization, and antimicrobial study. J Agric Food Chem, 2011;59(5):2056-2061.

41. Zheng X, Kan B, Gou M, et al. Preparation of MPEG-PLA nanoparticle for honokiol delivery in vitro. Int J Pharm. 2010;386(1-2):v262-267.

42. Moulari B, Lboutounne H, Pellequer Y, Guillaume YC, Millet J, Pirot F. Vectorization of Harungana madagascariensis Lam. Ex Poir. (Hypericaceae) ethanolic leaf extract by using PLG-nanoparticles: antibacterial activity assessment. Drug Dev Res. 2005;65(1):26-33.

43. Moulari B, Lboutounne H, Chaumont J, GuillaumeY, Millet J, PellequerY. Potentiation of the bacterial activity of Harungana madagascariensis Lam. Ex Poir. (Hypericaceae) leaf extract against oral bacteria using poly (D,L-lactide-co-glycolide) nanoparticles: in vitro study. Acta Odentol Scand. 2006;64(3):153-158.

44. Yen FL, Wu TZ, Lin LT, Cham TM, Lin CC. Nanoparticles formulation of Cuscuta chinensis prevents acetaminophen-induced hepatotoxicity in rats. Food Chem Toxicol. 2008;46(5):1771-1777.

45. Wu TZ, Yen FL, Lin LT, Tsai TR, Lin CC, Cham TM. Preparation, physicochemical characterization, and antioxidant effects of quercetin nanoparticles. Int J Pharm. 2008;346(1-2):160-168.

46. Min KH, Park K, Kim Y-S, et al Hydrophobically modified glycol chitosan nanoparticles-encapsulated camptothecin enhance the drug stability and tumor targeting in cancer therapy. $J$ Control Release. 2008;127(3):208-218.

47. Yen FY, Wu TH, Lin LT, Cham TM, Lin CC. Naringenin-loaded nanoparticles improve the physicochemical properties and the hepatoprotective effects of naringenin in orally-administered rats with CCl4-induced acute liver failure. Pharm Res. 2009;26(4):893-902.

48. Lacaille-Dubois MA, Mitaine-Offer AC. Triterpene saponins from polygalaceae. Phytochem Rev. 2005;4(2-3):139-149.

49. Paul S, Bhattacharyya SS, Boujedaini N, Khuda-Bukhshi AR. Anticancer potentials of root extract of polygala senega and its PLGA nanoparticles-encapsulated form. Evid Based Complement Alternat Med. 2011;2011(2011):1-13.

50. Martins S, Costa-Lima S, Carneiro T, Cordeiro-da-Silva A, Souto, EB, Ferreira DC. Solid lipid nanoparticles as intracellular drug transporters: an investigation of the uptake mechanism and pathway. Int $J$ Pharm. 2012;430(1-2):216-227.

51. Pardeike J, Hommoss A, Müller RH. Lipid nanoparticles (SLN, NLC) in cosmetic and pharmaceutical dermal products. Int J Pharm. 2009;366(1-2):170-184.

52. Souto EB, Severino P, Santana MHA, Pinho SC. Nanopartículas de lipídios sólidos: métodos clássicos de produção laboratorial [Solid lipid nanoparticles: classical methods of laboratory production]. Quim Nova. 2011;34(10):1762-1769. Portuguese.

53. Naahidi S, Jafari M, Edalat F, Raymond K, Khademhosseini A, Chen P. Biocompatibility of engineered nanoparticles for drug delivery. J Control Release. 2013;166(2):182-194.

54. Wissing SA, Kayserb O, Müller RH. Solid lipid nanoparticles forparenteral drug delivery. Adv Drug Deliv Rev. 2004;56(9):1257-1272.

55. Puri A, Loomis K, Smith B, et al. Lipid-based nanoparticles as pharmaceutical drug carriers: from concepts to clinic. Crit Rev Ther Drug Carrier Syst. 2009;26(6):523-580.
56. Das S, Chaudhury A. Recent advances in lipid nanoparticle formulations with solid matrix for oral drug delivery. AAPS Pharm Sci Tech. 2010;12(1):62-76.

57. Li H, Zhao X, Ma Y, Zhai G, Li L, Lou H. Enhancement of gastrointestinal absorption of quercetin by solid lipid nanoparticles. J Control Release. 2009;133(3):238-244.

58. Guo C, Yang C, Li Q, et al Development of a quercetin-loaded nanostructured lipid carrier formulation for topical delivery. Int $J$ Pharm. 2012;430(1-2):292-298.

59. Bose S, Michniak-Kohn B. Preparation and characterization of lipid based nanosystems for topical delivery of quercetin. Eur J Pharm Sci. 2013;48(3):442-452.

60. Kakkar V, Singh S, Singla D, Kaur IP. Exploring solid lipid nanoparticles to enhance the oral bioavailability of curcumin. Mol Nutr Food Res. 2011;55(3):495-503.

61. Mei Z, Huabing C, Weng T, Yang Y, Yang X. Solid lipid nanoparticle and microemulsion for topical delivery of triptolide. Eur J Pharm Biopharm. 2003;56(2):189-196.

62. Martins SM, Wendling T, Gonçalves VMF, Sarmento B, Ferreira DC. Development and validation of a simple reversed-phase HPLC method for the determination of camptothecin in animal organs following administration in solid lipid nanoparticles. J Chromatogr B. 2012;880(1):100-107.

63. Tiyaboonchai W, Tungpradit W, Plianbangchang P. Formulation and characterization of curcuminoids loaded solid lipid nanoparticles. Int J Pharm. 2007;337(1-2):299-306.

64. Hyde ST. Identification of Lyotropic Liquid Crystalline Mesophases. In: Holmberg K, Shah DO, Schwager MJ, editors. Handbook of Applied Surface and Colloid Chemistry. New York: Wiley; 2001: 299-332.

65. Rossetti FC, Fantini MCA, Carollo ARH, Tedesco AC, Bentley MVLB. Analysis of liquid crystalline nanoparticles by small angle X-ray diffraction: evaluation of drug and pharmaceutical additives influence on the internal structure. J Pharm Sci. 2011;100(7):2849-2857.

66. Chandrasekhar S, Madhusudana NV. Liquid crystals. Ann Rev Mater Sci. 1980;10:133-155.

67. Goodby JW, Bruce DW, Hird M, Imrie C, Neal M. An introduction to materials science: molecular topology in liquid crystals. J Mater Chem. 2001;11(4):2631-2636.

68. Sergeyev S, Pisula W, Geerts YH. Discotic liquid crystals: a new generation of organic semiconductors. Chem Soc Rev. 2007;36(12): 1902-1929.

69. Farkas E, Zelko R, Torok Gy, Racz I, Marton S. Influence of chlorhexidine species on the liquid crystalline structure of vehicle. Int J Pharm. 2001;213(1-2):1-5.

70. Formariz TP, Urban MCC, Silva-Júnior AA, Gremião MPD, Oliveira AG. Microemulsões e fases líquidas cristalinas como sistemas de liberação de fármacos [Microemulsions and liquid crystalline phases as delivery systems for drugs]. Rev Bras Cienc Farm. 2005;41(3):301-313. Portuguese.

71. Van Der Lubben IM, Konings FA, Borchard G, Verhoef JC, Junginguer HE. In vivo uptake of chitosan microparticles by murine Peyer's patches; visualization studies using confocoal laser scanning microscopy and immunohistochemistry. J Drug Target. 2001;9(1):39-47.

72. Goymann-Muller CC. Physicochemical characterization of colloidal drug delivery systems such as reverse micelles, vesicles, liquid crystals and nanoparticles for topical administration. Eur J Pharm Biopharm. 2004;58(2):343-356.

73. Hegmann T, Qi H, Marx VM. Nanoparticles in liquid crystals: synthesis, self-assembly, defect formation and potential applications. J Inorg Organomet Polym Mater. 2007;17(3):483-508.

74. Chorilli M, Prestes PS, Rigon RB, Leonardi GR, Chiavacci LA, Scarpa MV. Desenvolvimento de sistemas líquido-cristalinos empregando silicone fluido de co-polímero glicol e poliéter funcional siloxano [Development of systems employing liquid crystalline fluid silicone glycol copolymer and polyether functional siloxane]. Quim Nova. 2009;32(4):1036-1040. Portuguese.

75. Praça FSG, Medina WSG, Petrilli R, Bentley MVLB. Liquid crystal nanodispersions enable the cutaneous delivery of photosensitizer for topical PDT: fluorescence microscopy study of skin penetration. Curr Nanosci. 2012;8(4):535-540. 
76. Masson DS, Morais GG, Morais JM, et al. Polyhydroxy alcohols and peach oil addition influence on liquid crystal formation and rheological behavior of o/w mulsions. J Dispersion Sci Technol. 2005;26(4): 463-468.

77. Simões CM, Schenkel EP, Grace G, Mello JCP. Farmacognosia: da planta ao medicamento [Pharmacognosy: Plant drugs]. Rio Grande do Sul, Brazil: Porto Alegre; 2007. Portuguese.

78. Chandler M. Tecnologia água-em-óleo. Cosmet Toiletries (Port ed.) [Cosmetic Toiletries (Port ed.)]. 2002;14(6):46-52. Portuguese.

79. Bernardi DS, Pereira TA, Maciel NR, et al. Formation and stability of oil-in-water nanoemulsions containing rice bran oil: in vitro and in vivo assessments. J Nanobiotechnology. 2011;9(44):1-9.

80. Andrade FF, Santos ODH, Oliveira WP, Rocha-Filho PA. Influence of PEG-12 Dimethicone addition on stability and formation of emulsions containing liquid crystal. Int J Cosmetic Sci. 2007;29(3):211-218.

81. Morais GG, Santos ODH, Masson DS, Oliveira WP, Rocha-Filho PA. Development of $\mathrm{O} / \mathrm{W}$ emulsions with Annato Oil (Bixa orellana) containing liquid crystal. J Disper Sci Technol. 2005;26(5):591-596.

82. Santos ODH, Miotto JV, Morais JM, Rocha-Filho PA. Attainment of emulsions with liquid crystal from marigold oil using the required HLB method. J Disper Sci Technol. 2005;26(2):243-249.

83. Santos ODH, Rocha-Filho PA. Influence of surfactant on the therma behavior of marigold oil emulsions with liquid crystal phases. Drug Dev Ind Pharm. 2007;33(5):543-549.

84. Santos ODH, Morais JM, Andrade FF, Aguiar TA, Rocha-Filho PA Development of vegetable oil emulsions with lamellar liquid-crystalline structures. J Disper Sci Technol. 2011;32(3):433-438.

85. Chorilli M, Leonardi GR, Oliveira AG, Scarpa MV. Lipossomas em formulações dermocosméticas [Dermocosmetic liposome formulations]. Infarma. 2004;16(7-8):75-79. Portuguese.

86. Chorilli M, Rimério TC, Oliveira AG, Scarpa MV. Estudo da estabilidade de lipossomas unilamelares pequenos contendo cafeína por turbidimetria [Study of the stability of small unilamellar liposomes containing caffeine turbidimetric]. Rev Bras Farm. 2007;88(4)194-199. Portuguese

87. Andrade CAS, Correia MTS, Coelho LCBB, Nascimento SC, SantosMagalhães NS. Antitumor activity of Cratylia mollis lectin encapsulated into liposomes. Int J Pharm. 2004;278(2):435-445.

88. Priprem A, Watanatorn J, Sutthiparinyanont S, Phachonpai W, Muchimaupura S. Anxiety and cognitive effects of quercetin liposomes in rats. Nanomed Nanotech Biol Med. 2008;4(1):70-78.
89. El-Samaligy MS, Afifi NN, Mahmoud EA. Evaluation of hybrid liposomes-encapsulated silymarin regarding physical stability and in vivo performance. Int J Pharm. 2006;319(1-2):121-129.

90. Kim S, Turker MS, Chi EY, Sela S, Martin GM. Preparation of multivesicular liposomes. Biochim Biophys Acta. 1983;728(3): 339-348.

91. Katre NV, Asherman J, Schaefer H, Hora M. Multivesicular liposome (DepoFoam) technology for the sustained delivery of insulin-like growth factor-I (IGF-I). J Pharm Sci. 1998;87(11):1341-1346.

92. Zhong H, Deng Y, Wang X, Yang B. Multivesicular liposome formulation for the sustained delivery of breviscapine. Int J Pharm. 2005;301(1-2):15-24

93. Watanabe M, Kawano K, Toma K, Hattori Y, Maitani Y. In vivo antitumor activity of camptothecin incorporated in liposomes formulated with an artificial lipid and human serum albumin. J Control Release. 2008;127(3):321-328.

94. Silva PB. Síntese, caracterização e investigação das atividades biológicas de complexos de cobre (II) contendo moléculas bioativas e ligantes nitrogenados [Synthesis, characterization and investigation of the biological activities of complexes of copper (II) containing bioactive molecules and nitrogenous ligands]. [Thesis]. Araraquara, Brazil: Instituto de Química, UNESP; 2012. Portuguese.

95. Oliveira AG, Scarpa MV. Microemulsões I: fundamentos teóricos da formação do sistema microemulsionado [Microemulsion I: theoretical training of the microemulsion system]. Infarma. 2001;13(9-10): 73-79. Portuguese.

96. Oliveira AG, Scarpa MV, Cera LFR. Microemulsões II: aplicações de liberação de fármacos [Microemulsions II: applications for drug delivery]. Infarma. 2002;14(7-8):76-80. Portuguese.

97. Mezadri H. Desenvolvimento de nanoemulsões contendo extratos dos frutos de Syagrus romanzoffiana (Cham.) Glassman e estudo fitoquímico desses extratos [Development of nanoemulsions containing extracts of fruits of Syagrus romanzoffiana (Cham.) Glassman and phytochemical study of these extracts]. [Dissertation] Ouro Preto, Brazil: Faculdade de Ciências Farmacêuticas, UFOP; 2010. Portuguese.
International Journal of Nanomedicine

\section{Publish your work in this journal}

The International Journal of Nanomedicine is an international, peerreviewed journal focusing on the application of nanotechnology in diagnostics, therapeutics, and drug delivery systems throughout the biomedical field. This journal is indexed on PubMed Central,

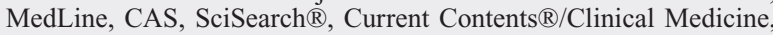

\section{Dovepress}

Journal Citation Reports/Science Edition, EMBase, Scopus and the Elsevier Bibliographic databases. The manuscript management system is completely online and includes a very quick and fair peer-review system, which is all easy to use. Visit http://www.dovepress.com/ testimonials.php to read real quotes from published authors. 